\title{
The effect of music on the activity level of children'
}

\section{Abstract}

The activity of 5 and 6 yr.old children was measured in a specially designed playroom under conditions of silence and two types of music, fast and slow. Activity rates were higher during the intervals when music was played, with fast music having the more marked effect. Music did not affect the variability of activity, which showed a steady decline during the time spent in the room.

\section{Problem}

Although a great many stimulus variables are assumed to influence the activity level of children, there have been few attempts to quantify these effects. One of the major impediments to work in this area has been a lack of adequate methodology for effectively measuring free play activity in children (Cromwell et al, 1963)。

Depending upon the selection played, music has been shown to increase or decrease the physiological activity of young children as measured by their galvanic skin responses (Zimny \& Weidenfeller, 1962). The present study investigated the effects of music on the activity level of 5 and $6 \mathrm{yr}$. old children as they played in a specially designed playroom (Fig. 1). Method

The room, $15 \mathrm{ft}$ square, with a carpeted floor and acoustically treated ceiling, contained the following toys:

(a) An electric train layout, surrounded by plexiglass walls, occupied one corner of the room. Protruding from the front side of the layout was a crank, which when turned caused the train to move on its tracks at a speed proportional to the rate of the crank turning up to a preset maximum.

(b) A colorful, life-size painting of a clown was mounted on one of the walls. Protruding from the picture, and hinged to the wall, were two wooden arms which held musical cymbals. By grasping the arms, the child could bang the cymbals together.

(c) A pedal car, mounted on blocks, was designed so that rotation of the pedals caused one of its rear wheels to turn and lights on its dashboard to flash.

(d) Ten light bulbs in five colors were mounted in two adjacent columns on a stimulus panel which was attached to a small table. A bright red wooden lever protruded from the table and each depression of the lever caused one of the bulbs to turn off and a different one to light.

(e) A standard spring-type rocking horse was mounted to the floor in the center of the room. The horse could be rocked either back and forth or up and down.

(f) A $16 \mathrm{~mm}$ continuous loop movie projector was housed in a wooden box containing an 18 in square

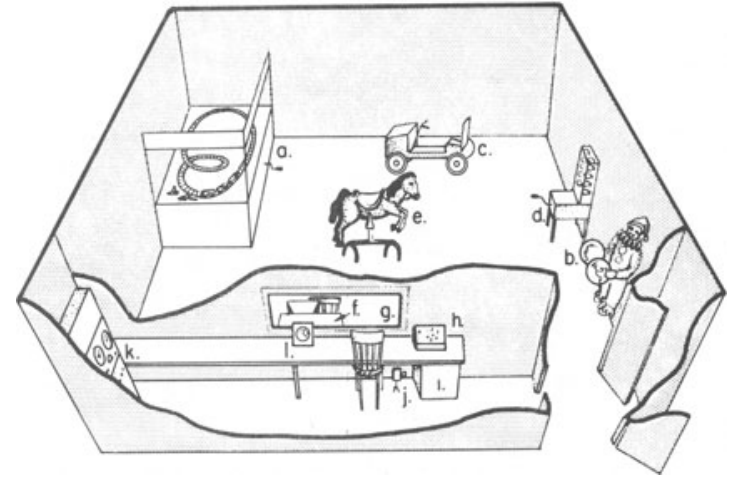

Fig. 1. Sketch of play room and adjoining control room..(a) Electric train. (b) Clown with cymbals. (c) Pedal car. (d) Light game. (e) Rocking horse. (f) Projector. (g) One-way vision window. (h) Clock selector switch. (i) Bank of counters and clocks. (j) Camera. (k) Control panel containing electronic equipment and tape recorder. (1) Timer.

sheet of ground glass. A color movie of jungle animals was projected on the rear of the glass and was visible to the child who was seated in front of it. The projector was activated only when the rate at which the child turned a nearby crank exceeded a preset minimum. Faster turning had no effect on the projector's speed.

Adjoining the activity room was a control room with a one-way window through which the experimenter could observe the child. A panel containing six counters and six clocks was located in the control room. Each counter and clock was assigned to a different toy. The number of crank turns, horse rocks, lever presses, cymbal contacts and pedal rotations was automatically recorded on the counters by means of microswitches and other devices located on the toys. By observing the child and manipulating a rotary switch the examiner was able to keep the appropriate clock activated while the child was playing with a particular toy.

The effects of two different pieces of music were studied. Three min. selections from Offenbach's Gaite Parisianne (Columbia ML 5946) and Bach's Air for the G String (Columbia ML 5065) were chosen because the former was judged to be fastand exciting, the latter slow and soothing.

The children were tested alone, one at a time. The experimenter structured the situation by telling the child that she was interested in which kind of toys children liked, and that in order to find this out, she would let him play in a toy room and then ask him which toy he liked best. A total of 29 children, 16 boys and 13 girls, were tested with both musical selections. In order to counterbalance for sequence effects, 15 children heard the fast selection first and the remainder heard the slow one first. Each child spent a total of $12 \mathrm{~min}$. in the room. The $12 \mathrm{~min}$. were 


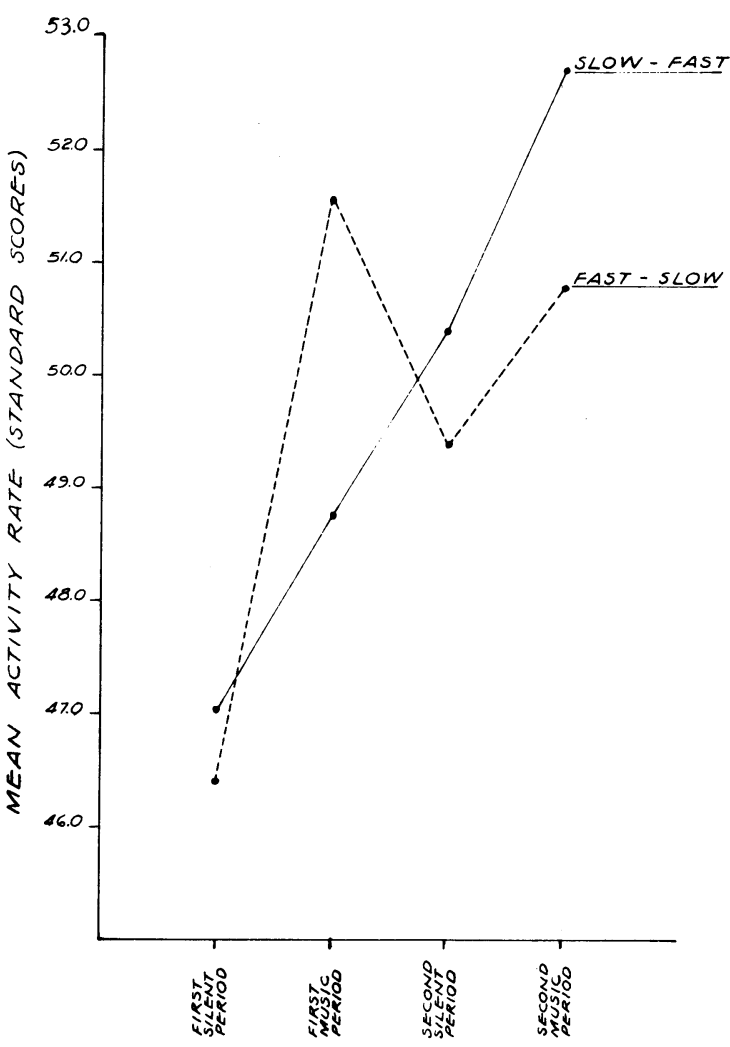

Fig. 2. Mean activity rate during each of the four $3 \mathrm{~min}$. periods. Data plotted separately for the two sequence groups.

divided into four $3 \mathrm{~min}$. periods. One selection was played during the second period, the other during the fourth period. The first and third periods were silent. Readings on the clocks and counters were automatically photographed when the child entered the room and at the end of each $3 \mathrm{~min}$. period thereafter. Frequency on each counter was divided by the elapsed time (in 10ths of a sec.) shown on the clock paired with that counter, yielding activity rates for the toys. The rates on each toy were transformed into standard scores (mean $=50$, standard deviation $=10$ ), so that they could be averaged into a single measure. This average activity rate was determined separately for each of the four 3 min. periods.

\section{Results and Diseussion}

The average activity rates for the two groups of children are presented in Fig, 2. Rates were significantly higher during the music periods $(F=9.30, d f=1 / 28$, $\mathrm{p}<.01$ ), and a comparison of the two musical selections revealed reliably higher rates during fast music $(F=7.06$, df $=1 / 26, p<.02)$. There was a tendency for rates to increase over time regardless of the type of music played, but this effect was reliable only at the .10 level $(F=2.94, \mathrm{df}=1 / 26)$.

The variability of the children's activity was measured by determining the average number of times they changed from one toy to the next. This measure, which is presented in Fig. 3, failed to show any effects of music. However, the children became less variable as they spent more time in the room. In a comparison

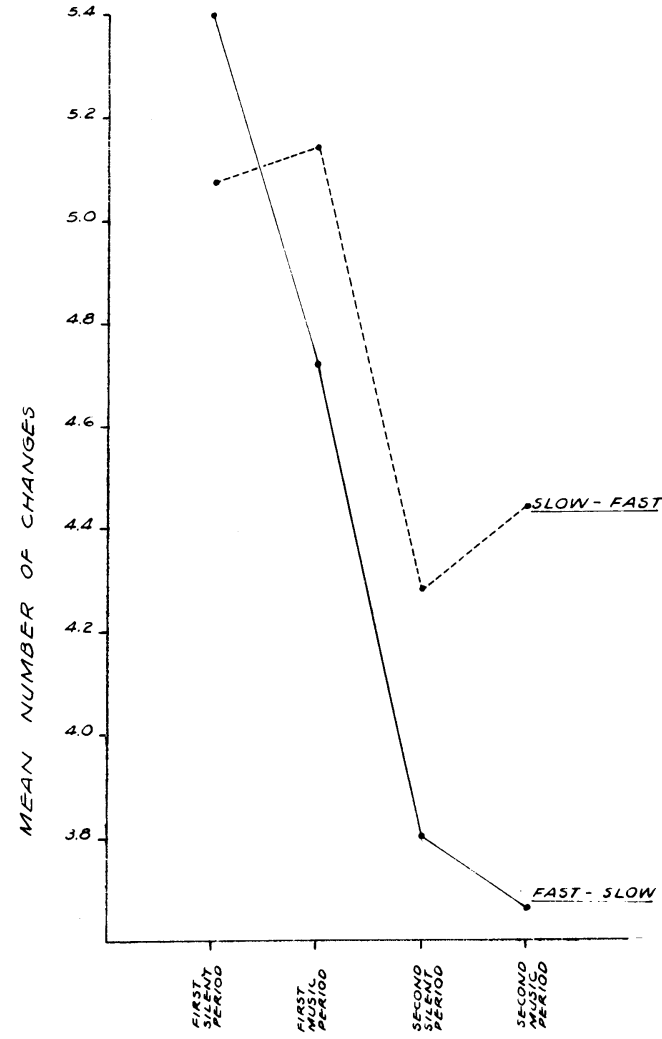

Fig. 3. Mean number of changes in toys during each of the four 3 min. periods.

of the first and second music period, this decrease was significant $(F=4.42, \mathrm{df}=1 / 26, \mathrm{p}<.05)$.

Previous reports have indicated that some musical selections have a greater effect on behavior than others. Jazz increased the reading rate of college students while other types of music were found to have no effect (Freeburne \& Fleischer, 1952). Using subjective evaluations, Simons (1964) found that music had a stimulating effect on 9 to 31 mo. old children and that their increased activity level was a function of the type of music played. The musical selections used in those studies as well as the present one differed in a number of expressive components such as timbre, rhythm and tempo, all or some of which may affect activity level. The present method of measuring play activity provides a useful tool for exploring those components as well as other variables which affect the activity level of children.

\section{References}

Cromwell, R. L., Baumeister, A., \& Hawkins, W. F. Research in activity level. In N. R. Ellis (Ed.), Handbook of mental deficiency. New York: McGraw-Hill, 1963. P. 632.

Freeburne, C. M., \& Fleischer, M. S. The effect of music distraction upon reading rate and comprehension. J. educ. Psychol., 1952, $43,101-109$.

Simons, G. M. Comparisons of incipient music responses among very young twins and singletons. J. Res. music Educ., 1964, $12,212-226$.

Zimny, G. H., \& Weidenfeller, E. W. Effects of music upon GSR of children. Child Develpm., 1962, 33, 891-896.

\section{Notes}

1. This study was supported by Grant MH 07240 from the National Institute of Mental Health. 